\title{
PROPUESTA PARA VALIDAR LOS MATERIALES ESCRITOS PRELIMINARES, REALIZADOS POR LAS UNIDADES O DEPENDENCIAS PRODUCTORAS DE MATERIALES
}

\section{PROPOSAL TO VALIDATE THE PRELIMINARY WRITTEN MATERIALS BY PRODUCER MATERIALS UNITS}

\section{Arturo Azofeifa-Céspedes ${ }^{1}$ aazofeifa@uned.ac.cr Universidad Estatal a Distancia, Costa Rica}

\author{
Volumen 8, Número 1 \\ 30 de mayo de 2017 \\ pp. $311-334$
}

Recibido: 27 de enero de 2017

Aprobado: 5 de mayo de 2017

\footnotetext{
${ }^{1}$ Magister en Administración de Proyectos. Magister en Auditoría Financiera Forense. Actualmente es Investigador en el Centro de Investigación y Evaluación Institucional de la UNED. Profesor de la cátedra de Ciencias Policiales de la UNED. Profesor unive rsitario en diferentes asignaturas, grados, carreras y universidades. Correos electrónicos: aazofeifa@uned.ac.cr / arturoazofeifa@gmail.com
}

Propuesta para validar los materiales escritos preliminares realizados por las unidades o dependencias productoras de materiales

Arturo Azofeifa-Céspedes

DOI : http://dx.doi.org/10.22458/caes.v8i1.1790

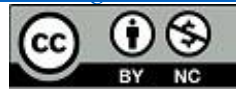




\section{Resumen}

La calidad de los materiales puestos al servicio de los estudiantes y docentes es fundamental para el aprovechamiento de cualquier esfuerzo en los procesos de enseñanza-aprendizaje. Mediante un estudio bibliográfico y comparativo se compilarán las mejores prácticas utilizadas para eventualmente ser aplicadas a conveniencia, y según las particularidades de las unidades o dependencias productoras de materiales. Este trabajo propone una metodología, a partir de una revisión de documentos disponibles, que permita evaluar el material en versión preliminar, a fin de identificar las oportunidades de mejora para elaborar la versión final. Evaluar es una de las etapas más importantes dentro del proceso enseñanza-aprendizaje, ya que establece los logros que se han realizado a lo largo del proceso educativo.

Palabras clave: Unidad académica, materiales, preliminar, evaluación.

\section{Abstract}

The quality of the materials put to the service of them learners and teaching is fundamental for the use of any effort in them processes of teaching-learning. Through a study bibliographic and comparative is compiled them best practices used to eventually be applied to convenience and according to the particularities of the units or units producing materials. This paper proposes a methodology, based on a review of available documents, which are assessing the material in draft, in order to identify opportunities for improvement to develop the final version. Evaluate is one of the most important stage in the teaching-learning process because it establishes the achievements that have been made throughout the educational process.

Keywords: Academic unit, materials, preliminary, assessment.

Propuesta para validar los materiales escritos preliminares realizados por las unidades o dependencias productoras de materiales

Arturo Azofeifa-Céspedes

DOI : http://dx.doi.org/10.22458/caes.v8i1.1790

\section{(c) (i) (8)}


REVISTA ELECTRÉNICA CALIDAD EN LA EDULACIÍN SUPERIIRR

Instituta de Gestión de la Calidad Académica

Universidad Estatal a Distancia, Costa Rica
ISSN: I659-4703, VDL. 8(I) ENERD-JUNID, 2017: 311-334

http://investiga.uned.ac.cr/revistas/index.php/revistacalidad

Соггеq: revistacalidad国uned.ac.сг

DOI : http://dx.doi.org/10.22458/caes.v8i1.1790

\section{Introducción}

Normalmente, en las instituciones educativas la elaboración de materiales escritos, que son requeridos por las diferentes acciones formativas y asignaturas que se ofrecen, son elaboradas por unidades o dependencias productoras de materiales. Es una función tan importante, que es una práctica casi generalizada que no se contraten personas externas para que lo realicen.

Estas unidades o dependencias productoras de materiales deben contar con una diversidad de disciplinas entre sus funcionarios o colaboradores, permitiendo con esto ofrecer una alta calidad académica en sus producciones, esencialmente mediante una gestión didáctica depurada, posibilitando que sean utilizadas tanto dentro como fuera del país y de las propias instituciones.

Este documento es una propuesta para validar los materiales que se realizan para apoyar los procesos de aprendizaje, realizados por unidades o dependencias productoras de materiales, con el objetivo de brindar un aseguramiento más adecuado en el importante proceso de pasar las versiones preliminares a las definitivas.

Es a final de cuentas, una responsabilidad de las unidades o dependencias productoras de materiales en coordinación con otras áreas y dependencias vinculadas, la implementación y ejecución de lo que en este documento se propone, además de las recomendaciones que mejor se adapten a sus intereses y necesidades.

Propuesta para validar los materiales escritos preliminares realizados por las unidades o dependencias productoras de materiales

Arturo Azofeifa-Céspedes

DOI : http://dx.doi.org/10.22458/caes.v8i1.1790

(c) (i) (8) 
REVISTA ELECTRÉNICA CALIDAD EN LA EDULACIÍN SUPERIIRR

Instituta de Gestión de la Calidad Académica

Universidad Estatal a Distancia, Costa Rica
ISSN: 1659-4703, VUL. 8(I) ENERD-JUNID, 2017: 311-334

http://investiga.uned.ac.cr/revistas/index.php/revistacalidad

Cоггес: revistacalidad国uned.ac.сг

DOI : http://dx.doi.org/10.22458/caes.v8i1.1790

La finalización del material se considera como la etapa inicial de la validación, entendiéndose con esto que la propuesta parte de un material concluido sobre el cual se debe decidir si será oficializado o no, es decir, si se publica o no.

\section{Fundamentación conceptual}

Con la teoría y la propuesta metodológica incluidas en este documento, se espera contribuir al cumplimiento de los objetivos planteados por aquellas unidades o dependencias responsables de la producción de los materiales utilizados en las diferentes acciones formativas. Se espera, además, ayudar a estas unidades o dependencias a dar respuesta a las siguientes interrogantes:

1. ¿Cuáles son los procesos actuales de revisión y evaluación de los materiales que son susceptibles a ser mejorados?

2. ¿Cuáles estrategias se deben implementar para dar seguimiento a la gestión de los materiales académicos?

3. ¿Cómo debe realizarse la evaluación de las unidades didácticas en versión preliminar?

\section{Metodología}

Mediante la revisión de los documentos disponibles (Libros, artículos, ensayos, entre otros), relacionados con los procesos de validación de materiales didácticos, se realizará una propuesta metodológica de evaluación que permita determinar las falencias de la versión

Propuesta para validar los materiales escritos preliminares realizados por las unidades o dependencias productoras de materiales

Arturo Azofeifa-Céspedes

DOI : http://dx.doi.org/10.22458/caes.v8i1.1790

(c) (i) (5)

Artículo protegido por licencia Creative Commons 
REVISTA ELECTRÉNICA CALIDAD EN LA EDULACIÍN SUPERIIRR

Instituta de Gestión de la Calidad Académica

Universidad Estatal a Distancia, Costa Rica
ISSN: I659-4703, VDL. 8(I) ENERD-JUNID, 2017: 311-334

http://investiga.uned.ac.cr/revistas/index.php/revistacalidad

Corгed: revistacalidad回uned.ac. сг

DOI : http://dx.doi.org/10.22458/caes.v8i1.1790

preliminar de una unidad didáctica, a fin de mejorar el material didáctico y utilizarlo en su versión final.

Para este trabajo se realizó una revisión de la literatura publicada en los últimos diez años, acerca de los elementos más importantes relacionados con la validación y revisión de materiales académicos impresos. Se tomaron en cuenta, en su mayoría, estudios de los años 2005 a 2015, y se incluyeron solo aquellos originales que se consideró brindarían más valor a esta propuesta, seleccionando para ser revisados aquellos autores o documentos más importantes dentro del tema de estudio.

Otro factor que caracteriza la literatura utilizada en este trabajo, es la importancia de sus autores, muchos de ellos son grandes referentes del tema de estudio, también su obra es frecuentemente citada en trabajos académicos y de investigación, libros, artículos, ensayos, y hasta en trabajos finales de graduación, entre otros.

Así mismo, se revisaron las bases de datos Digitalia, Ebsco, E-libro y Proquest, en los idiomas inglés y español.

\section{Revisión de la literatura}

Con el objetivo de facilitar la comprensión y el alcance de esta propuesta, se han identificado referencias, bibliografía u otros materiales que contribuyen, guían y orientan el problema de investigación.

Propuesta para validar los materiales escritos preliminares realizados por las unidades o dependencias productoras de materiales

Arturo Azofeifa-Céspedes

DOI : http://dx.doi.org/10.22458/caes.v8i1.1790

(c) (i) (5) 
REVISTA ELECTRÉNICA CALIDAD EN LA EDULACIÍN SUPERIIRR

Instituta de Gestión de la Calidad Académica

Universidad Estatal a Distancia, Costa Rica
ISSN: I659-4703, VDL. 8(I) ENERD-JUNID, 2017: 311-334

http://investiga.uned.ac.cr/revistas/index.php/revistacalidad

Corгed: revistacalidad回uned.ac. сг

DOI : http://dx.doi.org/10.22458/caes.v8i1.1790

Para Hernández, Fernández y Baptista (2014), la revisión de la literatura es un "paso de investigación que consiste en detectar, consultar y obtener la bibliografía y otros materiales útiles para los propósitos del estudio, de los cuales se extrae y recopila información relevante y necesaria para el problema de investigación" (p. 61). Por lo tanto, la revisión bibliográfica de la presente propuesta abarca los siguientes apartados:

\subsection{Evaluación}

El Ministerio de Planificación Nacional y Política Económica (2012) define evaluación como: "una valoración, un análisis sistemático y objetivo de un conjunto de criterios de valor que permiten emitir juicios y/o medir algo" (p. 10).

Los resultados y otra información relevante que se genere producto de procesos evaluativos deben servir como insumos en la toma de decisiones y en el mejoramiento de productos 0 gestiones desarrolladas.

Evaluando es posible conocer y determinar si todos los recursos son bien utilizados, si los objetivos son alcanzados, si el proceso de enseñanza y aprendizaje se lleva a cabo como se espera y si se presentan los resultados que se desean.

No debe existir un momento específico para evaluar, puede ser al momento de entregar un resultado, asignación u tarea, pero también puede servir para diagnosticar, incluso puede ser recurrente y constante, ósea, que no se detiene durante el horizonte de la actividad formativa. Es conveniente caracterizar la evaluación para determinar su importancia implícita.

Propuesta para validar los materiales escritos preliminares realizados por las unidades o dependencias productoras de materiales

Arturo Azofeifa-Céspedes

DOI : http://dx.doi.org/10.22458/caes.v8i1.1790

(c) (i) (5) 
REVISTA ELECTRÉNICA CALIDAD EN LA EDULACIÓN SUPPERIIR

Instituta de Gestión de la Calidad Académica

Universidad Estatal a Distancia, Costa Rica
ISSN: 1659-4703, VUL. 8(I) ENERD-JUNID, 2017: 311-334

http://investiga.uned.ac.cr/revistas/index.php/revistacalidad

Cоггес: revistacalidad国uned.ac.сг

DOI : http://dx.doi.org/10.22458/caes.v8i1.1790

\subsubsection{Características de una buena evaluación}

La evaluación no se escapa de poseer elementos deseables como lo puedes ser la calidad, profundidad u complejidad, es claro que debe tener indicadores relacionados con su efectividad.

Evaluando se persigue ser eficiente, dando buen uso a los recursos financieros e instruccionales, cumpliendo con el tiempo destinado al desarrollo de la actividad, pero sin olvidar que el estudiante debe aprender, en el mejor de los casos, generando buenas experiencias y sensaciones en los todos los participantes.

Una buena evaluación debe contar con una serie de características que garanticen su valía y credibilidad. Sobre esto el Ministerio de Planificación Nacional y política Económica (2012) aporta el siguiente cuadro:

\section{Cuadro 1. Características de una buena evaluación.}

\begin{tabular}{|l|l|}
\hline \multicolumn{1}{|c|}{ CARACTERÍSTICA } & \multicolumn{1}{c|}{ DESCRIPCIÓN } \\
\hline Orientación hacia los usuarios & $\begin{array}{l}\text { Los resultados deben ser presentados y } \\
\text { socializados de una manera que aumente la } \\
\text { probabilidad de que incidan en la toma de } \\
\text { decisiones. }\end{array}$ \\
\hline Calidad de los resultados & $\begin{array}{l}\text { Los resultados deben basarse en una metodología y } \\
\text { técnicas de levantamiento y análisis de datos } \\
\text { pertinentes y aceptados por los involucrados. }\end{array}$ \\
\hline Claridad del reporte & $\begin{array}{l}\text { Los reportes deben describir claramente el } \\
\text { programa que está siendo evaluado, incluyendo su } \\
\text { contexto y sus propósitos, los procedimientos y los }\end{array}$ \\
\hline
\end{tabular}

Propuesta para validar los materiales escritos preliminares realizados por las unidades o dependencias productoras de materiales

Arturo Azofeifa-Céspedes

DOI : http://dx.doi.org/10.22458/caes.v8i1.1790

\section{(c) (1) (8)}


REVISTA ELECTRÉNICA CALIDAD EN LA EDULACIÍN SUPPERIDR

Instituta de Gestión de la Calidad Académica

Universidad Estatal a Distancia, Costa Rica
ISSN: 1659-4703, VQL. 8(I) ENERD-JUNID, 20I7: 311-334

http://investiga.uned.ac.cr/revistas/index.php/revistacalidad

Corгed: revistacalidad回uned.ac. сг

DOI : http://dx.doi.org/10.22458/caes.v8i1.1790

\begin{tabular}{|l|l|}
\hline Credibilidad & $\begin{array}{l}\text { hallazgos de la evaluación, de tal manera que se dé } \\
\text { la información esencial en un formato de fácil } \\
\text { comprensión. }\end{array}$ \\
\hline Participación y Transparencia & $\begin{array}{l}\text { Los evaluadores deben ser confiables y } \\
\text { competentes y no estar sometidos a intereses que } \\
\text { puedan distorsionar el resultado. }\end{array}$ \\
$\begin{array}{ll}\text { Las evaluaciones tienen que considerar las } \\
\text { perspectivas y los intereses de los diversos } \\
\text { involucrados de la intervención en todas las fases } \\
\text { de la evaluación. Requieren de una comunicación } \\
\text { transparente con todos aquellos actores que estén } \\
\text { involucrados en o afectados por la evaluación. }\end{array}$ \\
\hline Accesibilidad de la información & $\begin{array}{l}\text { Los resultados de la evaluación deberían hacerse } \\
\text { accesibles para los diversos involucrados, } \\
\text { adaptando los canales y medios de información a } \\
\text { las necesidades de cada grupo de actores. }\end{array}$ \\
\hline Imparcialidad & $\begin{array}{l}\text { Las evaluaciones deben proveer una valoración } \\
\text { completa y justa de la información encontrada. } \\
\text { Opiniones divergentes y conflictos de intereses } \\
\text { deben ser discutidos abierta y honestamente, para } \\
\text { que estos no comprometan los procesos y } \\
\text { resultados de evaluación. }\end{array}$ \\
\hline Viabilidad & $\begin{array}{l}\text { La evaluación debe ser ejecutada de una manera } \\
\text { que sea política y técnicamente viable y no interfiera } \\
\text { en los procesos propios de la intervención. } \\
\text { Las evaluaciones deben ser diseñadas y } \\
\text { conducidas respetando y protegiendo los derechos } \\
\text { y el bienestar de los seres humanos involucrados. } \\
\text { Debe asegurarse que estos no sean lastimados ni } \\
\text { amenazados. }\end{array}$ \\
\hline $\begin{array}{l}\text { Protección de derechos de los } \\
\text { involucrados }\end{array}$
\end{tabular}

Fuente: Ministerio de Planificación Nacional y Política Económica (2012)

Propuesta para validar los materiales escritos preliminares realizados por las unidades o dependencias productoras de materiales

Arturo Azofeifa-Céspedes

DOI : http://dx.doi.org/10.22458/caes.v8i1.1790

(c) (i) (5)

Artículo protegido por licencia Creative Commons 
REVISTA ELECTRÉNICA CALIDAD EN LA EDULACIÍN SUPERIIRR

Instituta de Gestión de la Calidad Académica

Universidad Estatal a Distancia, Costa Rica
ISSN: 1659-4703, VUL. 8(I) ENERD-JUNID, 2017: 311-334

http://investiga.uned.ac.cr/revistas/index.php/revistacalidad

Саггес: revistacalidad国uned. ас.сг

DOI : http://dx.doi.org/10.22458/caes.v8i1.1790

\subsection{Unidad didáctica}

Es una unidad de programación de enseñanza con un tiempo determinado. En donde los objetivos de aprendizaje deben estar estrechamente vinculados con la forma, metodología y recursos destinados al proceso de enseñanza.

La Universidad Estatal a Distancia (s.f.) brinda su propia definición:

Es el material didáctico escrito elaborado en la UNED que contiene el desarrollo de los contenidos de una asignatura o de un curso, de acuerdo con los objetivos de aprendizaje, evaluación y metodología previamente establecida por el grupo de especialistas en el proceso de planificación curricular (p. 77).

Relacionado con el concepto de unidad didáctica (López, 2005) manifiesta:

La Unidad Didáctica expresa la organización del proceso de aprendizaje. Es el principal instrumento para orientar las actividades del formador, guiar el proceso de aprendizaje y el uso de los recursos formativos. Por ello se considera la Unidad Didáctica como el elemento básico de la programación formativa (p. 336).

También, el autor (García Aretio, 2001) brinda su propia definición:

Un conjunto integrado, organizado y secuencial de los elementos básicos que conforman el proceso de enseñanza-aprendizaje (motivación, relaciones con otros conocimientos, objetivos, contenidos, métodos y estrategias, actividades y evaluación) con sentido propio, unitario y completo que permite a los estudiantes, tras su estudio, apreciar el resultado de su trabajo. (p. 221)

Basado en las definiciones anteriores, es posible resaltar elementos comunes, como son la organización, la relevancia de secuenciar e integrar los procesos, todo en aras del máximo aprovechamiento y aprendizaje del estudiante. Si es claro, que el estudiante es el centro y objeto del proceso de enseñanza aprendizaje, pero los recursos son escasos y se deben dar

Propuesta para validar los materiales escritos preliminares realizados por las unidades o dependencias productoras de materiales

Arturo Azofeifa-Céspedes

DOI : http://dx.doi.org/10.22458/caes.v8i1.1790

(c) (i) (5)

Artículo protegido por licencia Creative Commons 
REVISTA ELECTRÉNICA CALIDAD EN LA EDULACIÍN SUPERIIRR

Instituta de Gestión de la Calidad Académica

Universidad Estatal a Distancia, Costa Rica
ISSN: 1659-4703, VUL. 8(I) ENERD-JUNID, 2017: 311-334

http://investiga.uned.ac.cr/revistas/index.php/revistacalidad

Cоггес: revistacalidad国uned.ac.сг

DOI : http://dx.doi.org/10.22458/caes.v8i1.1790

cuentas por su utilización. Entonces, la unidad didáctica es el claro ejemplo del orden imperante y necesario dentro de las actividades formativas.

\subsubsection{Estructura de la unidad didáctica}

Para Alcántara (2007) idealmente una unidad podría tener la siguiente estructura mínima:

1. Objetivos didácticos. Coherentes con los objetivos generales y referenciales. Es una enunciación de las capacidades previstas que debe alcanzar el alumnado al final de la unidad.

2. Contenidos. Saberes organizados de manera armónica, y que se enuncian como conceptos, procedimientos y actitudes.

3. Metodología. Estilo de enseñanza, organización de los grupos, tiempos y espacios y materiales empleados.

4. Actividades. Medios para alcanzar los objetivos previstos. Se suele establecer diferentes tipos de actividades que abarcan la recogida de ideas previas, actividades introductorias, de desarrollo, de síntesis y de expresión en diferentes ámbitos.

- Evaluación. No solo de los resultados obtenidos, sino de la unidad en sí. (p. 18)

Conocer la estructura de la unidad didáctica facilita la funcionalidad de la misma.

\subsubsection{Funciones de la unidad didáctica}

Las funciones de la unidad didáctica se sintetizan en el siguiente cuadro:

Propuesta para validar los materiales escritos preliminares realizados por las unidades o dependencias productoras de materiales

Arturo Azofeifa-Céspedes

DOI : http://dx.doi.org/10.22458/caes.v8i1.1790

(c) (i) (8) 


\section{Cuadro 2. Funciones de la unidad didáctica.}

1. Dar un grado de estandarización al proceso formativo.

2. Presentar los contenidos formativos de manera lógica y de forma secuencial.

3. Evitar descompensaciones en el momento de presentar los contenidos formativos.

4. Obligar a los formadores a analizar los contenidos formativos antes de realizar la acción formativa.

5. Ordenar la actividad formativa en un formato fácil de revisar.

6. Establecer una manera de presentar los contenidos formativos.

7. Relacionar las ayudas a facilitar, los materiales necesarios y los equipos a utilizar.

8. Proporcionar un instrumento para dar continuidad entre las diferentes partes de la acción formativa, especialmente cuando intervienen diferentes formadores.

Fuente: López Camps (2005)

\section{Propuesta de validación de unidades didácticas preliminares}

Derivado de la revisión de los documentos disponibles, se presenta la siguiente propuesta para validar las unidades didácticas preliminares. Se debe resaltar el hecho de que únicamente se encontraron valoraciones teóricas o conceptuales, todas muy parecidas, pero no fue posible encontrar un instrumento u herramienta matricial, estadísticas, entre otras, que contribuyan en el proceso de decisión de la eventual publicación o no del material didáctico.

Propuesta para validar los materiales escritos preliminares realizados por las unidades o dependencias productoras de materiales

Arturo Azofeifa-Céspedes

DOI : http://dx.doi.org/10.22458/caes.v8i1.1790

(c) (i) (5) 
Todas las ponderaciones porcentuales, valores absolutos, factores o participantes incluidos en esta propuesta deben ser valorados por las autoridades competentes o responsables de la producción de los materiales impresos, o por quienes estos designen, con el propósito de que sean ajustados en beneficio del aumento de la calidad de los materiales producidos o que lo serán.

En esta propuesta, inicialmente se han determinado los factores más importantes relacionados con el proceso evaluativo, además de su peso porcentualmente representado:

\section{Cuadro 3. Participantes en el proceso de evaluación}

\begin{tabular}{|l|c|}
\hline \multicolumn{1}{|c|}{ FACTORES } & PORCENTAJE \\
\hline Grupos de estudiantes & $25 \%$ \\
\hline Aprobación de asignatura & $20 \%$ \\
\hline Oportunidades de mejora & $20 \%$ \\
\hline Tutores o profesionales calificados & $35 \%$ \\
\hline TOTALES & $\mathbf{1 0 0} \%$ \\
\hline
\end{tabular}

Fuente: Elaboración propia, 2017.

\subsubsection{Identificación de los participantes}

A cada participante se le aplicará una matriz, en la cual será posible determinar el peso porcentual que aportará en la validación final de la unidad didáctica, además de los criterios que justifican la relevancia de su participación en el proceso.

Propuesta para validar los materiales escritos preliminares realizados por las unidades o dependencias productoras de materiales

Arturo Azofeifa-Céspedes

DOI : http://dx.doi.org/10.22458/caes.v8i1.1790

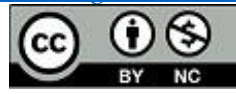




\section{$\checkmark$ Grupos de estudiantes}

Serán seleccionados, al menos 20 estudiantes, quienes ya hayan cursado la asignatura, los cuales conformarán 4 grupos. Cada grupo de estudiantes valorará la unidad didáctica y seleccionará los siguientes criterios de evaluación:

\section{Figura 1. Participación grupos de estudiantes}

\begin{tabular}{|c|c|c|c|c|}
\hline FACTORES & PONDERACIÓN & CONCEPTO & PONDERACIÓN & RESULTADO \\
\hline \multirow{7}{*}{ Desarrollo temático } & \multirow{7}{*}{$30 \%$} & La manera en que se exponen los temas me facilita la comprensión. & $15 \%$ & $5 \%$ \\
\hline & & El desarrollo de los temas corresponde a los objetivos propuestos. & $15 \%$ & $5 \%$ \\
\hline & & $\begin{array}{l}\text { Los temas son suficientes para cumplir los propósitos de la } \\
\text { asignatura. }\end{array}$ & $15 \%$ & $5 \%$ \\
\hline & & $\begin{array}{l}\text { Los ejercicios de autoevaluación y las actividades complementarias } \\
\text { me dan la preparación necesaria para cumplir con la evaluación de la } \\
\text { asignatura. }\end{array}$ & $10 \%$ & $3 \%$ \\
\hline & & Los temas expuestos están actualizados. & $15 \%$ & $5 \%$ \\
\hline & & Los temas son útiles para mi formación. & $15 \%$ & $5 \%$ \\
\hline & & $\begin{array}{l}\text { Los temas están redactados de manera que puedo comprenderlos } \\
\text { fácilmente. }\end{array}$ & $15 \%$ & $5 \%$ \\
\hline \multirow{6}{*}{ Estructura } & \multirow{6}{*}{$20 \%$} & $\begin{array}{l}\text { La secuencia de los temas está relacionada con las orientaciones de } \\
\text { la asignatura. }\end{array}$ & $20 \%$ & $4 \%$ \\
\hline & & $\begin{array}{l}\text { La estructura de los temas me permite alcanzar los objetivos de la } \\
\text { asignatura. }\end{array}$ & $20 \%$ & $4 \%$ \\
\hline & & Organización de temas. & $15 \%$ & $3 \%$ \\
\hline & & Organización de actividades. & $15 \%$ & $3 \%$ \\
\hline & & Organización de ejemplos. & $15 \%$ & $3 \%$ \\
\hline & & Organización de ejercicios. & $15 \%$ & $3 \%$ \\
\hline
\end{tabular}

Propuesta para validar los materiales escritos preliminares realizados por las unidades o dependencias productoras de materiales

Arturo Azofeifa-Céspedes

DOI : http://dx.doi.org/10.22458/caes.v8i1.1790

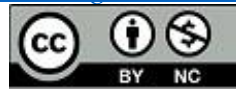

Artículo protegido por licencia Creative Commons 


\begin{tabular}{|c|c|c|c|c|}
\hline \multirow{24}{*}{$\begin{array}{l}\text { Estrategias de } \\
\text { enseñanza }\end{array}$} & \multirow{24}{*}{$30 \%$} & Formato del material (Dimensiones) & $5 \%$ & $2 \%$ \\
\hline & & Orden de páginas. & $4 \%$ & $1 \%$ \\
\hline & & Uso del color. & $4 \%$ & $1 \%$ \\
\hline & & Tamaño de la letra. & $5 \%$ & $2 \%$ \\
\hline & & Textos y sombreados. & $4 \%$ & $1 \%$ \\
\hline & & Recuadros. & $5 \%$ & $2 \%$ \\
\hline & & Uso de viñetas. & $5 \%$ & $2 \%$ \\
\hline & & Destacados (Negras, cursivas) & $3 \%$ & $1 \%$ \\
\hline & & Figuras, imágenes y fotografías. & $3 \%$ & $1 \%$ \\
\hline & & Íconos y señales. & $3 \%$ & $1 \%$ \\
\hline & & Gráficos y esquemas. & $3 \%$ & $1 \%$ \\
\hline & & Mapas conceptuales. & $3 \%$ & $1 \%$ \\
\hline & & Redacción. & $5 \%$ & $2 \%$ \\
\hline & & Objetivos. & $5 \%$ & $2 \%$ \\
\hline & & Ejemplos. & $5 \%$ & $2 \%$ \\
\hline & & Resúmenes. & $5 \%$ & $2 \%$ \\
\hline & & Introducciones. & $5 \%$ & $2 \%$ \\
\hline & & Preguntas. & $4 \%$ & $1 \%$ \\
\hline & & Cuadros. & $4 \%$ & $1 \%$ \\
\hline & & Glosario. & $4 \%$ & $1 \%$ \\
\hline & & Títulos y subtítulos. & $4 \%$ & $1 \%$ \\
\hline & & Notas al margen o al pie de página. & $4 \%$ & $1 \%$ \\
\hline & & Índice temático. & $4 \%$ & $1 \%$ \\
\hline & & Enlaces a internet. & $4 \%$ & $1 \%$ \\
\hline \multirow{4}{*}{ Metodología } & \multirow{4}{*}{$10 \%$} & $\begin{array}{l}\text { La metodología utilizada por el autor es adecuada para mi } \\
\text { aprendizaje. }\end{array}$ & $26 \%$ & $3 \%$ \\
\hline & & $\begin{array}{l}\text { Los ejercicios y las respuestas de autoevaluación así como las } \\
\text { actividades complementarias me facilitan el proceso de aprendizaje. }\end{array}$ & $26 \%$ & $3 \%$ \\
\hline & & $\begin{array}{l}\text { La relación entre contenidos y objetivos es adecuada para mi } \\
\text { aprendizaje. }\end{array}$ & $24 \%$ & $2 \%$ \\
\hline & & $\begin{array}{l}\text { Los ejercicios de autoevaluación y las actividades complementarias } \\
\text { cumplen con los objetivos propuestos del curso. }\end{array}$ & $24 \%$ & $2 \%$ \\
\hline \multirow{3}{*}{ Contexto educativo } & \multirow{3}{*}{$5 \%$} & $\begin{array}{l}\text { La asignatura cumple con mis expectativas como estudiante de esta } \\
\text { institución. }\end{array}$ & $30 \%$ & $2 \%$ \\
\hline & & $\begin{array}{l}\text { La carrera cumple con mis expectativas como estudiante de esta } \\
\text { institución. }\end{array}$ & $40 \%$ & $2 \%$ \\
\hline & & La unidad didáctica cumple con los objetivos de la asignatura. & $30 \%$ & $2 \%$ \\
\hline \multirow{4}{*}{ Aspectos generales } & \multirow{4}{*}{$5 \%$} & Es la primera vez que utilizo unidades didácticas de esta institución. & $25 \%$ & $1 \%$ \\
\hline & & En general la unidad didáctica que acabo de evaluar me satisface. & $25 \%$ & $1 \%$ \\
\hline & & Recomiendo el uso de esta unidad didáctica. & $25 \%$ & $1 \%$ \\
\hline & & Podría utilizar esta unidad didáctica como libro de consulta. & $25 \%$ & $1 \%$ \\
\hline
\end{tabular}

Fuente: Elaboración propia, 2017.

Propuesta para validar los materiales escritos preliminares realizados por las unidades o dependencias productoras de materiales

Arturo Azofeifa-Céspedes

DOI : http://dx.doi.org/10.22458/caes.v8i1.1790

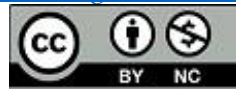

Artículo protegido por licencia Creative Commons 
De las 4 evaluaciones resultantes se realizará un promedio simple que será con el que se alimente la matriz de valoración. El máximo puntaje que podrá asignar este factor será de $25 \%$.

\section{$\checkmark$ Aprobación de asignatura}

Para sacar el porcentaje que otorgará a la evaluación, este factor se debe aplicar el siguiente indicador:

$$
=\frac{\text { Cantidad de estudiantes aprobados }}{\text { Cantidad de estudiantes matriculados }} \quad-100
$$

El resultado de ese índice será anual y debe interpretarse según la siguiente tabla:

\section{Cuadro 4. Aprobación de asignatura}

\begin{tabular}{|c|c|}
\hline RANGO APROBACIÓN & PORCENTAJE \\
\hline $81-100 \%$ & $20 \%$ \\
\hline $51-80 \%$ & $15 \%$ \\
\hline $0-50 \%$ & $10 \%$ \\
\hline
\end{tabular}

Fuente: Elaboración propia, 2017.

Cualquier designación de las funciones o responsabilidades derivada de esta propuesta será gestionada por las autoridades competentes o responsables de la producción de los materiales

Propuesta para validar los materiales escritos preliminares realizados por las unidades o dependencias productoras de materiales

Arturo Azofeifa-Céspedes

DOI : http://dx.doi.org/10.22458/caes.v8i1.1790

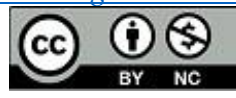


REVISTA ELECTRÉNICA CALIDAD EN LA EDULACIÍN SUPERIIRR

Instituta de Gestión de la Calidad Académica

Universidad Estatal a Distancia, Costa Rica
ISSN: 1659-4703, VUL. 8(I) ENERD-JUNID, 2017: 311-334

http://investiga.uned.ac.cr/revistas/index.php/revistacalidad

Cоггес: revistacalidad国uned.ac.сг

DOI : http://dx.doi.org/10.22458/caes.v8i1.1790

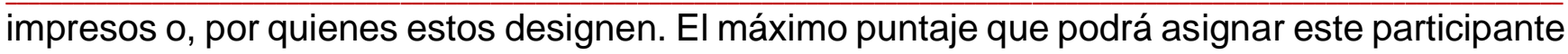
será de $20 \%$.

\section{$\checkmark$ Oportunidades de mejora}

Este factor se relaciona con toda comunicación oficial relacionada con errores o modificaciones requeridas, expresadas por estudiantes, funcionarios, tutores o público en general, dicha comunicación deberá realizarse mediante el correo electrónico u otra vía con la que cuente la institución educativa.

Para estos efectos, una oportunidad de mejora pueden ser errores, omisiones que induzcan a errores, adiciones o modificaciones en los materiales impresos.

Tanto los ejemplos de oportunidades de mejora como la manera en que se recolectarán estas, será determinado por las autoridades competentes o responsables de la producción de los materiales impresos o por quienes estos designen.

El resultado relacionado con este participante será anual en número de veces y no repetitivo, y debe interpretarse según la siguiente tabla:

\section{Cuadro 5. Oportunidades de mejora}

\section{RANGO OPORTUNIDADES PORCENTAJE}

\begin{tabular}{l|l}
\hline $0-10$ oportunidades & $20 \%$
\end{tabular}

Propuesta para validar los materiales escritos preliminares realizados por las unidades o dependencias productoras de materiales

Arturo Azofeifa-Céspedes

DOI : http://dx.doi.org/10.22458/caes.v8i1.1790

(c) ${ }_{\mathrm{BY}}(\mathrm{SC}$

Artículo protegido por licencia Creative Commons 


\begin{tabular}{|c|c|}
\hline $11-25$ oportunidades & $15 \%$ \\
\hline 25 o más oportunidades & $10 \%$ \\
\hline & \\
\hline
\end{tabular}

Fuente: Elaboración propia, 2017.

El máximo puntaje que podrá asignar este participante será de $20 \%$.

\section{$\checkmark$ Tutores o profesionales calificados}

Serán considerados al menos 3 tutores o profesionales calificados, quienes realizarán una evaluación independiente. Cada tutor o profesional calificado valorará la unidad didáctica y seleccionará los siguientes criterios de evaluación:

Propuesta para validar los materiales escritos preliminares realizados por las unidades o dependencias productoras de materiales 


\section{Figura 2. Tutores o profesionales calificados}

\begin{tabular}{|c|c|c|c|c|}
\hline FACTORES & PONDERACIÓN & CONCEPTO & PONDERACIÓN & RESULTADO \\
\hline \multirow{7}{*}{ Desarrollo temático } & \multirow{7}{*}{$30 \%$} & $\begin{array}{l}\text { La manera en que se exponen los temas me facilita el proceso } \\
\text { enseñanza-aprendizaje. }\end{array}$ & $15 \%$ & $5 \%$ \\
\hline & & El desarrollo de los temas corresponde a los objetivos propuestos. & $15 \%$ & $5 \%$ \\
\hline & & $\begin{array}{l}\text { Los temas son suficientes para cumplir los propósitos de la } \\
\text { asignatura. }\end{array}$ & $15 \%$ & $5 \%$ \\
\hline & & $\begin{array}{l}\text { Los ejercicios de autoevaluación y las actividades complementarias } \\
\text { me ayudan para cumplir con la evaluación de la asignatura. }\end{array}$ & $10 \%$ & $3 \%$ \\
\hline & & Los temas expuestos están actualizados. & $15 \%$ & $5 \%$ \\
\hline & & Los temas son útiles para la formación de los aprendientes. & $15 \%$ & $5 \%$ \\
\hline & & $\begin{array}{l}\text { Los temas están redactados de manera que puedo exponerlos } \\
\text { fácilmente. }\end{array}$ & $15 \%$ & $5 \%$ \\
\hline \multirow{6}{*}{ Estructura } & \multirow{6}{*}{$20 \%$} & $\begin{array}{l}\text { La secuencia de los temas está relacionada con las orientaciones de } \\
\text { la asignatura. }\end{array}$ & $20 \%$ & $4 \%$ \\
\hline & & $\begin{array}{l}\text { La estructura de los temas me permite alcanzar los objetivos de la } \\
\text { asignatura. }\end{array}$ & $20 \%$ & $4 \%$ \\
\hline & & Organización de temas. & $15 \%$ & $3 \%$ \\
\hline & & Organización de actividades. & $15 \%$ & $3 \%$ \\
\hline & & Organización de ejemplos. & $15 \%$ & $3 \%$ \\
\hline & & Organización de ejercicios. & $15 \%$ & $3 \%$ \\
\hline
\end{tabular}

Propuesta para validar los materiales escritos preliminares realizados por las unidades o dependencias productoras de materiales

Arturo Azofeifa-Céspedes

DOI : http://dx.doi.org/10.22458/caes.v8i1.1790

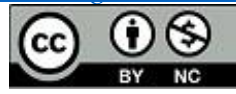

Artículo protegido por licencia Creative Commons 


\begin{tabular}{|c|c|c|c|c|}
\hline & & Formato del material (Dimensiones) & $5 \%$ & $2 \%$ \\
\hline & & Orden de páginas. & $4 \%$ & $1 \%$ \\
\hline & & Uso del color. & $4 \%$ & $1 \%$ \\
\hline & & Tamaño de la letra. & $5 \%$ & $2 \%$ \\
\hline & & Textos y sombreados. & $4 \%$ & $1 \%$ \\
\hline & & Recuadros. & $5 \%$ & $2 \%$ \\
\hline & & Uso de viñetas. & $5 \%$ & $2 \%$ \\
\hline & & Destacados (Negras, cursivas) & $3 \%$ & $1 \%$ \\
\hline & & Figuras, imágenes y fotografías. & $3 \%$ & $1 \%$ \\
\hline & & Íconos y señales. & $3 \%$ & $1 \%$ \\
\hline & & Gráficos y esquemas. & $3 \%$ & $1 \%$ \\
\hline Estrategias de & & Mapas conceptuales. & $3 \%$ & $1 \%$ \\
\hline enseñanza & $30 \%$ & Redacción. & $5 \%$ & $2 \%$ \\
\hline & & Objetivos. & $5 \%$ & $2 \%$ \\
\hline & & Ejemplos. & $5 \%$ & $2 \%$ \\
\hline & & Resúmenes. & $5 \%$ & $2 \%$ \\
\hline & & Introducciones. & $5 \%$ & $2 \%$ \\
\hline & & Preguntas. & $4 \%$ & $1 \%$ \\
\hline & & Cuadros. & $4 \%$ & $1 \%$ \\
\hline & & Glosario. & $4 \%$ & $1 \%$ \\
\hline & & Títulos y subtítulos. & $4 \%$ & $1 \%$ \\
\hline & & Notas al margen o al pie de página. & $4 \%$ & $1 \%$ \\
\hline & & Índice temático. & $4 \%$ & $1 \%$ \\
\hline & & Enlaces a internet. & $4 \%$ & $1 \%$ \\
\hline & & $\begin{array}{l}\text { La metodología utilizada por el autor es adecuada para mi función } \\
\text { docente. }\end{array}$ & $26 \%$ & $3 \%$ \\
\hline Metodología & $10 \%$ & $\begin{array}{l}\text { Los ejercicios y las respuestas de autoevaluación, así como las } \\
\text { actividades complementarias me facilitan el proceso de enseñanza. }\end{array}$ & $26 \%$ & $3 \%$ \\
\hline IMletodologıa & $10 \%$ & $\begin{array}{l}\text { La relación entre contenidos y objetivos es adecuada para mi función } \\
\text { docente. }\end{array}$ & $24 \%$ & $2 \%$ \\
\hline & & $\begin{array}{l}\text { Los ejercicios de autoevaluación y las actividades complementarias } \\
\text { cumplen con los objetivos propuestos de la asignatura. }\end{array}$ & $24 \%$ & $2 \%$ \\
\hline & & $\begin{array}{l}\text { La asignatura cumple con mis expectativas como tutor de esta } \\
\text { institución. }\end{array}$ & $30 \%$ & $2 \%$ \\
\hline Contexto educativo & $5 \%$ & $\begin{array}{l}\text { La carrera cumple con mis expectativas como tutor de esta } \\
\text { institución. }\end{array}$ & $40 \%$ & $2 \%$ \\
\hline & & La unidad didáctica cumple con los objetivos de la asignatura. & $30 \%$ & $2 \%$ \\
\hline & & Es la primera vez que utilizo unidades didácticas de esta institución. & $25 \%$ & $1 \%$ \\
\hline Aspectos generales & $5 \%$ & En general la unidad didáctica que acabo de evaluar me satisface. & $25 \%$ & $1 \%$ \\
\hline & & Recomiendo el uso de esta unidad didáctica. & $25 \%$ & $1 \%$ \\
\hline & & Podría utilizar esta unidad didáctica como libro de consulta. & $25 \%$ & $1 \%$ \\
\hline
\end{tabular}

Fuente: Elaboración propia, 2017.

\footnotetext{
Propuesta para validar los materiales escritos preliminares realizados por las unidades o dependencias productoras de materiales Arturo Azofeifa-Céspedes 
REVISTA ELECTRÉNICA CALIDAD EN LA EDULACIÍN SUPERIIRR

Instituta de Gestión de la Calidad Académica

Universidad Estatal a Distancia, Costa Rica
ISSN: 1659-4703, VUL. 8(I) ENERD-JUNID, 2017: 311-334

http://investiga.uned.ac.cr/revistas/index.php/revistacalidad

Cоггес: revistacalidad国uned.ac.сг

DOI : http://dx.doi.org/10.22458/caes.v8i1.1790

De las 3 evaluaciones resultantes se realizará un promedio simple que será con el que se alimente la matriz de valoración. El máximo puntaje que podrá asignar este participante será de $35 \%$.

\subsubsection{Matriz general de valoración}

De la interacción de las diferentes evaluaciones de los factores se construye la siguiente matriz general de valoración, la cual debería arrojar un resultado que oriente y guíe la decisión final sobre las acciones de mejora de la unidad didáctica.

\section{$\checkmark$ Valoración final del material}

Para que la unidad didáctica pase de preliminar a definitivo, su valoración debe conseguir el puntaje mínimo establecido, según la siguiente tabla:

\section{Cuadro 6. Valoración final del material}

\begin{tabular}{|c|c|c|}
\hline NIVEL & DESCRIPTOR & RANGO \\
\hline REDISEÑO & Debe plantearse un rediseño del material & $0-50 \%$ \\
\hline MODIFICACIONES & $\begin{array}{c}\text { Deben realizarse modificaciones sustanciales } \\
\text { en el material }\end{array}$ & $51-80 \%$ \\
\hline ACEPTABLE & $\begin{array}{c}\text { Deben realizarse modificaciones mínimas } \\
\text { (atención de oportunidades de mejora) }\end{array}$ & $81-100 \%$ \\
\hline
\end{tabular}

Fuente: Elaboración propia, 2017.

\section{$\checkmark$ Ejemplo de valoración positiva}

Se presenta la aplicación de la matriz de valoración con resultado positivo.

Propuesta para validar los materiales escritos preliminares realizados por las unidades o dependencias productoras de materiales

Arturo Azofeifa-Céspedes

DOI : http://dx.doi.org/10.22458/caes.v8i1.1790

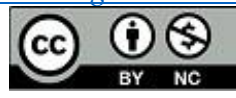




\section{Cuadro 7. Valoración positiva}

\begin{tabular}{|l|c|}
\hline \multicolumn{1}{|c|}{ FACTORES } & PORCENTAJE \\
\hline Grupos de estudiantes & $22 \%$ \\
\hline Aprobación de asignatura & $18 \%$ \\
\hline Oportunidades de mejora & $18 \%$ \\
\hline Tutores o profesionales calificados & $32 \%$ \\
\hline TOTALES & $\mathbf{9 0 \%}$ \\
\hline
\end{tabular}

\section{Debe ser definitivo ACEPTABLE}

Fuente: Elaboración propia, 2017.

\section{$\checkmark$ Ejemplo de valoración con modificaciones}

Se presenta la aplicación de la matriz de valoración con un resultado con modificaciones.

\section{Cuadro 8. Ejemplo de valoración con modificaciones}

\begin{tabular}{|l|c|}
\hline \multicolumn{1}{|c|}{ FACTORES } & PORCENTAJE \\
\hline Grupos de estudiantes & $17 \%$ \\
\hline Aprobación de asignatura & $13 \%$ \\
\hline Oportunidades de mejora & $15 \%$ \\
\hline Tutores o profesionales calificados & $28 \%$ \\
\hline TOTALES & $\mathbf{7 3 \%}$ \\
\hline
\end{tabular}

\section{Deben realizarse modificaciones MODIFICACIONES}

Fuente: Elaboración propia, 2017.

Propuesta para validar los materiales escritos preliminares realizados por las unidades o dependencias productoras de materiales

Arturo Azofeifa-Céspedes

DOI : http://dx.doi.org/10.22458/caes.v8i1.1790

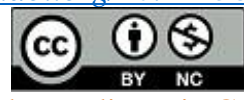




\section{Ejemplo de valoración negativa}

Se presenta la aplicación de la matriz de valoración con resultado negativo.

\section{Cuadro 9. Ejemplo de valoración negativa}

\begin{tabular}{|l|c|}
\hline \multicolumn{1}{|c|}{ FACTORES } & PORCENTAJE \\
\hline Grupos de estudiantes & $11 \%$ \\
\hline Aprobación de asignatura & $8 \%$ \\
\hline Oportunidades de mejora & $7 \%$ \\
\hline Tutores o profesionales calificados & $20 \%$ \\
\hline TOTALES & $\mathbf{4 6 \%}$ \\
\hline
\end{tabular}

Debe plantearse rediseño
REDISENO

Fuente: Elaboración propia, 2017.

Propuesta para validar los materiales escritos preliminares realizados por las unidades o dependencias productoras de materiales

Arturo Azofeifa-Céspedes

DOI : http://dx.doi.org/10.22458/caes.v8i1.1790

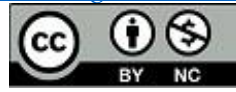


REVISTA ELECTRÉNICA CALIDAD EN LA EDULACIÓN SUPPERIIR

Instituta de Gestión de la Calidad Académica

Universidad Estatal a Distancia, Costa Rica
ISSN: I659-4703, VDL. 8(I) ENERD-JUNID, 2017: 311-334

http://investiga.uned.ac.cr/revistas/index.php/revistacalidad

Соггеq: revistacalidad国uned.ac.сг

DOI : http://dx.doi.org/10.22458/caes.v8i1.1790

\section{Conclusiones}

Después de realizar la propuesta de metodología preliminar evaluativa, se presentan las siguientes conclusiones:

1. Las autoridades responsables de la administración de la producción de los materiales impresos, o quienes estos designen, deben decidir cuál es la mejor metodología para realizar la evaluación de los materiales preliminares, pudiendo escoger la propuesta en este documento, o en su defecto proponer alguna supletoria que llegue a cumplir ese mismo objetivo.

2. La decisión de oficializar esta propuesta debe considerar factores tales como la disponibilidad de los recursos humanos y financieros, además del conocimiento mínimo que vuelva factible su aplicación, desarrollo e implementación.

3. Todo lo detallado en este documento constituye una propuesta, la cual se realiza con el único objetivo de fortalecer la importante labor de producir los materiales escritos que son piedra angular en los procesos de enseñanza-aprendizaje, además son indispensables para aprendientes y en la propia función docente.

4. Quienes estén involucrados en la producción de materiales deben acercarse a procesos que permitan evaluar su gestión. Por eso, esta propuesta debe ser considerada como un insumo, además que se le deben realizar las modificaciones que mejor se ajusten a sus propias necesidades y particularidades.

5. Se debe valorar, el involucrar otras dependencias de la institución educativa, que estratégicamente deberían conocer y valorar esta propuesta, con la finalidad de enriquecerla, para hacerla más útil y realista según objetivos establecidos.

Propuesta para validar los materiales escritos preliminares realizados por las unidades o dependencias productoras de materiales

Arturo Azofeifa-Céspedes

DOI : http://dx.doi.org/10.22458/caes.v8i1.1790

(c) (i) (8) 
REVISTA ELECTRÉNICA CALIDAD EN LA EDULACIÍN SUPERIIRR

Instituto de Gestión de la Calidad Académica

Universidad Estatal a Distancia, Costa Rica
ISSN: 1659-4703, VQL. 8(I) ENERD-JUNID, 20I7: 311-334

http://investiga.uned.ac.cr/revistas/index.php/revistacalidad

Corгed: revistacalidad回uned.ac. сг

DOI : http://dx.doi.org/10.22458/caes.v8i1.1790

\section{Referencias}

Alcántara Ahumada, C. (2007). Introducción a la programación de aula en educación infantil. Sevilla, España: Fundación ECOEM.

García Aretio, L. (2001). La educación a distancia: De la teoría a la práctica (1ª ed.). Barcelona, España: Editorial Ariel, S.A.

Hernández Sampieri, R., Fernández Collado, C., \& Baptista Lucio, P. (2014). Metodología de la investigación (6 ed.). México, D.F., México: McGraw Hill Educación.

Lafourcade Vives, P. D. (2002). Evaluación institucional (1ª ed.). San José, Costa Rica: Editorial Universidad Estatal a Distancia.

López Camps, J. (2005). Planificar la formación con calidad (1를. ed.). Madrid.

Medina Díaz, M. d., \& Verdejo Carrión, A. L. (2001). Evaluación del aprendizaje estudiantil (3ª ed.). San Juan, Puerto Rico: Isla Negra Editores.

Ministerio de Planificación Nacional y Política Económica. (2012). Manual gerencial para el diseño y ejecución de evaluaciones estratégicas de gobierno. San José, Costa Rica: Unidad de Comunicación - MIDEPLAN.

Universidad Estatal a Distancia. (s.f.). Glosario de términos curriculares para la Universidad Estatal a Distancia. San José, Costa Rica: Programa de Producción de Material Didáctico Escrito.

Propuesta para validar los materiales escritos preliminares realizados por las unidades o dependencias productoras de materiales

Arturo Azofeifa-Céspedes

DOI : http://dx.doi.org/10.22458/caes.v8i1.1790

(c) (i) (5) 